\title{
Social Virtuosity and the Improvising Voice
}

\author{
Phil Minton \& Maggie Nicols Interviewed by Chris Tonelli
}

\section{Introduction}

In 1977, an extraordinary album with the simple title Voice was released on Ogun Records. What made the record extraordinary was its focus on the free improvisation of only the title instrument. In his commentary on the record jacket, Ogun co-founder Keith Beal wrote that "It is not often that one sees a vocalist doing a jazz gig these days. When there are four of them it is very rare indeed and when these four vocalists are singing unaccompanied it must be unique." It was. Unfortunately, voice-only free jazz group performances are still relatively rare: although the precedent set by the vocalists on this album and other improvising vocalists has presented free jazz/improvisatory vocal practice as a creative option, and although the contemporary global free jazz/improvised music community currently includes hundreds of active improvising vocalists, old prejudices that see the voice as too emotional, insufficiently abstract, or lacking in rigour still linger and prevent the voice from becoming an equal player in the field of improvised music.

The following interview with Maggie Nicols and Phil Minton, two of the four vocalists who made up Voice, is a conversation with two of free jazz's most significant vocalists, a significance derived not only from their longevity ${ }^{1}$ and the innovations they are responsible for, ${ }^{2}$ but also from the ethics governing how their practices developed.

Minton's championing of unconventional vocal sounds is an ethical necessity for him. He argues that we've been "duped," cheated out of our full vocal potential by a culture that dictates how the voice should and should not be used. There is an ethic to the sounds he has chosen to work with, sounds marked as purposeless or childish in nearly all Western contexts. Minton seeks to rehabilitate these sounds, both for himself and for others who were told as children to stop making them despite the great joy and wonder they can hold. There is also an ethic to the generosity with which Minton devotes himself to helping others rebuild a relationship with the stolen parts of their voices. His Feral Choirs are inclusive gatherings that create a safe space to explore the voice both for those who consider themselves "singers" and for those who do not yet see themselves as such. As he explains below, it wasn't until he fully realized the positive effect these improvising choirs could have on participants who haven't had a public space to share their voices that he became truly devoted to creating such spaces.

Maggie Nicols is, perhaps, the improvising musician most responsible for promoting the notion that the crucial prerequisite for improvisation is social virtuosity. She has devoted herself to social and political activism, to cultivating inclusive spaces for creative practice, to examining how politics and creative practice can be blended to carve a space for women in male-dominated music cultures and to move improvised music away from pure abstraction towards a better awareness of injustice and inequality. Early in her career, Nicols worked with and was strongly influenced by John Stevens, a percussionist, composer, improviser, and educator whose ideas and beliefs-including devotion to community, education, and service; commitment to ensembles of mixed abilities; and faith in the endless richness of simple structures that level the improvisational playing field-she has continued, expanded upon, and complemented. Her twenty-five years organizing and hosting The Gathering (an unstructured, inclusive space for collective interplay that runs regularly in London and Carmarthenshire, Wales) stands as evidence, just one example among many, of her commitment to these principles.

For those interested in learning more about Nicols and Minton through their recordings, Voice is a good place to start. It is a rare document of a 1976 live performance by the group, which included singers Julie Tippetts and Brian Eley, and it displays rousing melodies and chants combined with dense textural vocality to form semi-improvised works that resist conflicting ideologies that might deem either simple melodies or textured noisescapes regressive.

Listeners may also be interested in going further back and experiencing Up Umeå (1969), the earliest document of Minton's work currently commercially available; it captures his early movement between trumpet and voice and the ways his voice engaged in a mimetic exchange with the saxophone of Lars Göran Ulander. From there, it is revealing to sample the contributions Minton made to Mike Westbrook's various projects throughout the 1970s and beyond, both for the fascinating ways the projects pastiched and détourned a variety of musical forms and to gain a sense of the politics fuelling some of the British jazz of that period. This politics is evident across a wide range of Westbrook and Minton's collaborations, from the parody of materialist display at the heart of the title track on Solid Gold Cadillac (1972) to the temporally and stylistically diverse protest anthems featured on Mike Westbrook's Brass Band Plays "For the Record" (1975) to the dreams of justice conveyed by settings of William Blake texts on Bright as Fire (1980) and Glad Day (2008). Evidence of the politics behind Minton's practice is also displayed on many of his collaborations 
with pianist Veryan Weston, including Songs From a Prison Diary (1991), a piece for piano, percussion, and choir composed by Minton and Weston and based on the writings of Ho Chi Minh, and Ways Out East, Ways Out West (2005), a recording that combines a selection of American protest songs and abstract improvisation with a reflection on the life of Russian anarchist Nestor Makhno. ${ }^{3}$

Equally important to understanding Minton's work is recognizing his interest in the politics of play, fully evident in the jovial moments of the "comprovisation" Mouthfull of Ecstacy (1996), a work by the Phil Minton Quartet (Minton, Weston, Roger Turner, and John Butcher) that builds structures and improvisations around excerpts from James Joyce's Finnegan's Wake. ${ }^{4}$ Another example of his politics of play can be found in the joy that ensues when five of the world's most active improvising vocalists get together: Five Men Singing (featuring Minton alongside Paul Dutton, Jaap Blonk, David Moss, and Makigami Koichi) contains tracks where we can hear these extraordinary singers playfully attempting to surprise, delight, and challenge one another. Minton's sense of humour is also evident in the titles of his four solo vocal recordings: A Doughnut in Both Hands (1981), A Doughnut in One Hand (1998), No Doughnuts in Hand (2008), and A Doughnut's End (2015). ${ }^{5}$ The importance of this series cannot be overstated, for these four records, by confusing and complicating entrenched notions of what vocal sounds are ugly and what are beautiful, challenge a pervasive order of the valuable and valueless.

Documents of Nicols' early work feature her in groups like John Stevens' Spontaneous Music Ensemble, Keith Tippett's Centipede, Paul Rutherford's Iskra groups, Ken Hyder's Talisker, and others. By the late 1970s, she developed a feminist consciousness that led to collaborations with other female improvisers. The self-titled, selfreleased cassette Feminist Improvising Group (1979) documents seven improvisations featuring Nicols alongside Georgina Born, Lindsay Cooper, Corine Liensol, Sally Potter, Anne-Marie Roelofs, Irène Schweizer, and Angèle Veltmeijer. This recording lacks the essential visual component of Nicols' work, but it reveals some of the constructive ways through which F.I.G. disrupted dominant, male-privileging modernist attitudes in improvised music.

Nicols' deep contribution to improvised music is also apparent on albums like Live at the Bastille, a trio performance from 1982 (with Joëlle Léandre and Lindsay Cooper) where she fearlessly moves between abstract vocalisations and stream of consciousness speech improvisations that blend the intimacy of personal confession and memory with examinations of the power structures that shape and constrain us all. Such material reminds us of the social processes that have led to or stood in the way of musicians sounding publicly, just as it resists the powerful illusion that music can function as an autonomous sphere, divorced from socio-political concerns.

The visual component so important to Nicols' work is masterfully displayed in Jubilee Concert, a beautifully filmed DVD release of a 2006 performance by the trio Les Diaboliques (Nicols, Léandre, and Schweizer) in celebration of their and Intakt Records' 20th anniversaries. Nicols frequently transforms the meanings of sounds with suggestive, referential movements and compelling theatrical interplay with other performers.

There is also a commercially available document of her work with The Gathering, entitled The Gathering - For John Stevens, that contains large ensemble realizations of Stevens' "Click Piece" and "Sustain Piece." The Gathering - For John Stevens demonstrates that respect for structured silence can be fostered in even very large improvising ensembles. Furthermore, this recording celebrates Nicols' devotion to an inclusive space where anyone can improvise brilliantly when given the necessary support.

These recordings, of course, only begin to scratch the surface of the many collaborations and projects between the two singers over five decades. There is a much broader discography waiting to be excavated by those inspired by these initial thoughts or by the interview that follows.

What follows is a transcript of a public interview Nicols and Minton gave at the Symposium on Voice, Agency, and Improvisation that took place in Guelph, Ontario on June 26, 2014, sponsored by the International Institute for Critical Studies in Improvisation and supported by the Guelph Jazz Festival, the Macdonald Stewart Art Centre, and the University of Guelph's Institute for Community Engaged Scholarship. My hope is that this interview will promote greater understanding of the work of two devoted improvisers and their fight against the politics that have marginalized voices in so many musical contexts.

Here, Nicols and Minton explore how the politics of distinct vocal practices shape the voice. Minton addresses the symbolic potential of instruments, like the voice, that have sonic signatures clearly unique from others of their type, while Nicols invokes the pressure singers often feel to mould their voices to existing timbral norms and minimize that palpable uniqueness. These thoughts align with philosopher Adriana Cavarero, who argues in her recent book For More Than One Voice that the voice, even more than the face, signifies the uniqueness of every individual. Minton 
and Nicols go beyond Cavarero, however, in drawing attention to how various vocal practices direct voices towards an impossible but idealized uniformity that Cavarero links to dehumanization.

Other threads in this discussion reinforce the richness of ensembles with mixed abilities, the rewards of valuing inclusion over aesthetic ideals, and the potential for improvisation to empower. Through their work with the Feral Choir and The Gathering, Minton and Nicols have modeled effective methods for improvisational practices to unite participants with divergent skills and experience while yielding rewards for all participants.

In describing how we can find meaning in unconventional vocal sounds, Nicols and Minton also criticize ideologies that dismiss these sounds as worthless or dangerous. Their devotion to these sounds, despite such pervasive denigration, should inspire us to do more to help make marginalized sounds, voices, and people heard.

\section{Interview}

Chris Tonelli: It makes me so incredibly happy to introduce to you Phil Minton and Maggie Nicols, who have come all the way from the U.K. to be with us today. We're very honoured they've made the trip.

It's a daunting task to introduce them, because they've both done so much important work for so long that a summary could hardly do it justice, but I'll mention a few points of importance. It's certainly arguable that no two figures have done more to make the voice an important part of free improvised music. Their improvisational vocal practices began in the late 1960s and have consistently contributed since then. Equally important has been their role as pedagogues. Maggie has, since the early 1970s, spearheaded a wide variety of initiatives to create accessible, inclusive spaces for improvisation. These include Contradictions, an open women's workshop and performance group, and The Gathering, a welcoming space for listening and experimentation that's been going on since 1990. Since the late 1980s, Phil has been working with his concept the Feral Choir, a workshop environment that seeks to put participants back in touch with the free vocal play that we'd all be engaging in if we weren't, ourselves, so domesticated. Both Phil and Maggie have touched countless lives with their groundbreaking and progressive approaches to improvisation. There's so much more that I could say, but I'll stop here and ask you to help me in welcoming them and thanking them for making this trip to Guelph.

Today's event is a celebration of improvisation involving the voice. So, that's where l'd like to begin our discussion. Could you start by giving us an overview of the path that led you to your particular vocal practices?

Phil Minton: It came from jazz, definitely.

Maggie Nicols: Yes. I would agree with that.

Phil Minton: I came from quite a conventional musical family, very fine singers, very lovely voices, but I was looking for something a little more. It was a period where it wasn't like today, where you can find out all the information about sounds, and music, and instruments. You can just switch on YouTube and hear Tuvan singing and music from all over the world. But when I first started listening to music, which would have been either listening to my parents singing at the piano (my father was a baritone, my mother was a soprano, my uncle was a tenor, and they'd be rehearsing sort of light operatic music), and then on the radio, probably in the late 1940s or early 1950s, I heard [sings for a moment in a Louis-Armstrong-like timbre] Louis Armstrong. Wow! What a voice. Louis Armstrong's voice got me interested in the jazz music of the time. And then, listening to Voice of America, a radio program that broadcast all the music of the American jazz of the time (the late 1950s: Ornette Coleman, Charles Mingus, John Coltrane, of course). It was from this music that I started to get interested in using my voice as an improvising instrument.

I was always quite surprised. Instruments always have this one colour, this one sound, like how I'm speaking now. It all has something in common: it's one sound. But I was always interested in the different colours, the different textures of the voice. It isn't like a tempered instrument. It isn't like something you buy in a shop, like a piano or trumpet.

Actually, trumpets are quite nice because they can change colour. I come from jazz. I was a jazz trumpet player for a time. 
Maggie Nicols: If I think back, actually, I first started improvising with my mother. She used to talk in made-up language and just go [she models these made up languages, alternating quickly between high pitches with squeaky timbres and low pitches with hoarse timbres]. We still do if we're angry with each other [she models the language while making choking gestures and other intense facial expressions]. It's a great way of relieving tension. I love soul music. I love ska. I love bebop. But it was through going down to Ronnie's [Ronnie Scott's Jazz Club in London], and then when Ronnie's place closed, the Old Place on Gerrard Street became the place where free jazz happened.

I think because I didn't see any women playing instruments, I just assumed that we were biologically not meant to play instruments. I know, it's sad, right? But, it's really how I felt. But, I had a hunger. I loved John Coltrane, I was obsessed with Bill Evans, I just fell in love with jazz, so maybe I had a hunger to hear a voice playing like that.

But, it is quite interesting what Phil says about timbre, because I think the great instrumentalists all say they are very influenced by song and singing: the jazz players before free improvisation talk about how they learned the words of the songs when they played. So, there is that sense of the voice influencing other instruments as well as us being influenced by instrumental music and hearing the voice in that.

But my big mentor was, of course, John Stevens. He was the one who made it possible for me to do it, because he actually invited me up to the Little Theatre Club. I'm going to do a couple of his pieces later in the afternoon workshop because I just feel he changed my life and opened it out for me to use my voice in a way where I felt respected as opposed to abused, which I did in many ways by some of the many musicians on the scene. But, I won't go into that.

Chris Tonelli: The idea of instruments getting into the voice is important. In many free jazz/free improvisation contexts, that has seemed to become okay in a way that it's not in certain other contexts, so I want to talk a little bit about instruments. I use the term "soundsinging" to refer to allowing more unconventional vocal and non-vocal oral sounds to enter your performances: it's a term that comes from Paul Dutton, who's going to be here on the artists' panel this afternoon and performing on tonight's concert. It's interesting to me that a lot of soundsingers did begin as trumpeters: Trevor Wishart, I believe, yourself Phil, I did, and perhaps others. Do you think, Phil, that there was something about that particular instrument that invited you into an unconventional vocal practice somehow?

Phil Minton: I don't think so. Not myself. Because I've always been playing with my voice since I was a small child. I was always experimenting with vocal sounds. As a small boy, I could do quite grown up sounding voices. I used to do Winston Churchill, Adolf Hitler. I found it quite fun. I was always playing with my voice and mother used to say, when she used to speak with me, "Oh, Philip, I never know who I'm speaking to. You always come back with a different sound." I don't know if that was just me.

Maggie Nicols: I think a lot of children do, actually. I mean, you go into any school playground and you just hear these incredible vocal sounds until we're all told "No, that's not music!" It's the same with painting: in any school, every single painting is like "wow" until, what happens, we're told that certain people are meant to go and be creative and other people are supposed to just get their noses down and do other jobs.

Chris Tonelli: The reason I chose the trumpet as an instrument. . .

Phil Minton: I thought it was easy [audience laughs] because it only had three buttons.

Chris Tonelli: Yes, that's important: the way that some instruments can be presented as intimidating or belonging to a group that we don't belong to. For me, it was that I could carry it home. I had a long walk home and this was one of the instruments that wouldn't be too daunting. Portability. This, of course, applies to the voice. We all have voices. You're both performers who have, I think, strong philosophies behind your music about community, strong politics in both of your backgrounds. Could you talk about the democracy of voice as an instrument?

Maggie Nicols: One of the things I feel is that if we're actually allowing ourselves not to feel like we've got to sound like a jazz singer, or a folk singer-unless that comes naturally-each of us has a unique voice. You know, when somebody you love, or your friend phones, you know it's them. So for me, the voice is both the most unique expression of an individual, but at the same time, when you sing with other voices there can be times when you can't tell one voice from another. I love that ambivalence, that you can, sometimes, just blend and it's just "wow!"—our voices merge and become one another. 
We've both said this (both Phil and I, independent of one another, have said): if you can breathe, you can sing! So, it's just about being alive. The voice is a sigh, a cry, laughter, everything, and, if you choose, then you can develop that, go deep into it, like when we were talking about Hawaiian falsetto singers that go into their bedrooms or sing along to records [referring to Dr. Kati Szego's paper presented earlier in the symposium]. That was very interesting to me because I've done a lot of singing along to records. I love the fact that as a vocalist there are many, many ways in to developing virtuosity, or flexibility, or whatever. But at the same token, you can sing with people who have never considered themselves a singer and create a social virtuosity, an amazing excellence of brilliance. Everybody can sound brilliant with the voice, and yet you can also choose to become absolutely one-pointed and develop the voice as far as you want. I love that contradiction.

Phil Minton: As you know, I do this (I've done it all over the world now) group called the Feral Choir. I was invited first in a music college in Sweden to do it. It was with trained singers mostly, and I wasn't really that happy with it in the early days, but then I got invited to do some in housing projects in France, and I did quite a tour around in France. The actual choral results weren't that impressive - the actual sound of the singers, it wasn't exactly what I wanted, how I was hearing it in my head-but afterwards, the people were so enthusiastic and loved it so much. They said, "Oh, we had such a great time. It was the first time we'd ever been onstage and sung and used our voices," and it really literally brought me to tears and I thought I really want to do this more in lots and lots of different situations. Now the aesthetic idea of trying to get a group of singers to sound like some preconceived idea I had in my head, that's gone. What happens now? Every time I do it, it's a new creation, and I'm hearing fantastic works of art every time I listen to a group of people singing. People are capable of such beautiful music.

There was this one woman I remember: all she basically did in the group was go "la la la la la." I thought she was taking the piss, actually. Afterwards, her husband came up and said how much she really enjoyed it, so now I try to use the limitations of people as well as the virtuoso. Obviously, there are some people that are fantastic as well. I'm trying to integrate the whole thing together with the people that have, perhaps, quite a small range of vocal ideas, more than say vocal range. With my warm-ups and introductions to the choir, I try to tell people there's all sorts of things you can do; it isn't about just singing "God Save the Queen" or "Happy Birthday," which is sometimes the only time people are used to singing-and they've often been told, when they're very small children, "you can't sing." Because, you know, children at birthday parties, somebody starts to sing and everybody comes in in a different key, and there's all these different notes. Sometimes it's amazingly avant-garde-actually [laughter], it sounds like Schoenberg-but often, it's when it happens at a very young age: kids are told they can't sing.

Maggie Nicols: Absolutely. The number of people you must have had that come in and say. . .

Phil Minton: "I can't sing."

Maggie Nicols: Yeah. I did my first workshop in 1969, and I was really anxious. I was so nervous. I'm glad I was nervous - people helped me as much—but since then, the number of people that come in and go "I can't sing, I can't sing"-and everybody can.

\section{Phil Minton: Yes.}

Maggie Nicols: I am very grateful to John Stevens. I must mention John again because I didn't realize until just before John died how self-conscious and how frightened he was about his own voice. He never admitted that. And come to think of it, he never sang, except when he was playing the drums and going "ahhhhh!" [she lets out a long yell]. You could hear him, and you never knew whether it was because you were doing something wrong [laughter] or he was really, really happy-because he had very, very strict pieces. But if you did those pieces, everybody sounded like a genius. That's what I love about John, that he was the master of mixed ability. One of the pieces that I'm going to do [in the workshop this afternoon], the Sustain Piece, I remember when he introduced it to me: he said, "it doesn't matter if your voice wavers or wobbles or croaks"-and that's because he was so damaged. I finally realized that he had been told. . .

Phil Minton: Probably at some birthday party somewhere. . .

Maggie Nicols: Yes, some teacher had told him that he couldn't sing, and all of a sudden (and this was at some community seminar on the voice that John admitted this), and of course all at once all of the community voice teachers wanted to get their hands on John, saying "yes, you can sing!" But he died not long after. So he waited until before he bloody died to tell us. But he did so much for the voice. He loved the human voice. He really, really did. And that was the thing: he could introduce pieces where. . . it was funny because we were talking about going into trance, 
but in actual fact, you would almost go into a very deep trance to the point where you discover techniques you didn't realize you had-and that's what I find interesting too. It's a bit like when they talk about people when there's a car, and there's somebody trapped under a car and all of a sudden they get this superhuman ability to lift that car off: I think there are places you can go where you all become genius. Because I do believe there's a genius in all of us, and I find that very exciting to explore that territory, individually and collectively.

Chris Tonelli: Absolutely, and it's something for us to remember in improvisation studies always: that there is a great value to mixed-ability ensembles-and you've both done so much to promote that idea.

We've hit on a theme that, in my writing, I call policing the voice: this moment at the birthday party when someone tells you not to or you can't sing. And I think one of the other times the voice gets policed, and this ties our conversation now to some of the things we were talking about in the papers this morning, is when there's a perception that the visual nature of the body, the way that the body is coded (as human, as male, as white, as aged, as classed), is perceived to be at odds with the way that the sounds we're making are coded. When audiences perceive that the visual and the sonic are not in line, sometimes they're either profoundly liberated or profoundly threatened. The main reason I'm interested in your music is that I've had powerful reactions to it: listening to it, I've felt that enlivening feeling, and I'm interested on a theoretical level in the question: "what happens when you do this?" You both use a lot of unconventional language that may be viewed in that way by a lot of audiences, and I think that when you see it for the first time, it can be profoundly shocking, but I also think that when you've seen it regularly for fourteen years, as I have, there are still always moments when these perceived dissonances between the visual and the sonic cause very powerful effects. Can you address that in any way? What happens when the visual and the sonic, at least how we're perceiving them, how we've coded them, don't line up?

Phil Minton: One of the things that happens is people think I'm angry. I'm making an angry sound, or I'm in pain. And, of course, you get the fact that I'm a white male, not even middle-aged anymore (I used to be for a time), and I'm not supposed to be doing this sort of thing. I don't know what I should be doing. I should be sitting at home by the fire? Warming my socks?

The voice has so many associations. The voice is never innocent, but then again, it's never guilty. I've never heard sounds that mean something. I'll go to Louis Armstrong's voice. It really sounds like he's in pain if you just think of it as a [sounds a sequence of pitches with multiphonic throat noise]. Aesthetically, in European culture, Christian culture, this is not a sound we hear. We don't hear it at all. For me, this has always been a little bit of a chance to juxtapose all these different sounds that aren't the sound that is supposed to be happening, or the sound that one person expects coming from a human voice, or a human.

Maggie Nicols: It's interesting because you [Dr. Kara Attrep] were talking about Yoko [Ono, in the paper Dr. Attrep delivered earlier in the day], and someone was saying she was growling like a bear. I thought, actually, I wouldn't mind if somebody said I was growling like a bear. I love the fact that the voice encompasses all of humanity and all the sounds of the universe. I love the fact that we have access to this infinite library.

There is a woman called Serena Roney-Dougal who wrote a book Where Science and Magic Meet. She's a parapsychologist and she mentioned that the conscious mind can hold seven things at once and the unconscious, or whatever you want to call it, literally an infinite amount. So, in a sense, you have access to this infinite library. So yeah, I think when you're in altered states sometimes, who knows what you're accessing. It could sound like a bear. Sometimes I am in pain. Sometimes I'm joyous. And some people will misunderstand, like Phil says: there's a solo piece up on Youtube and my mate, Del, she says to me, "Oh Mag, you really sound like you're writhing in pain," and I'm actually feeling quite joyous at that point. So yeah, it can be misinterpreted, but also, lots of times when it is, whatever I'm feeling is what comes out. And there is anger, and there is pain; and then it's also beyond all that. It's neutral: it's just sound. So, I'm quite interested in shape shifting between different things. I'm actually really accessing this evolving library-because it's not like a fixed thing. There was a scientist talking about that, saying it's not like there's this heavenly data somewhere and we just access it; it's almost like the universe is evolving all the time. So we're drawing on everything that's ever been, but also each new evolving moment. I love that fact that we're combing ancient and unknown, everything that's ever been, and it's unfolding as we do it as well.

I've probably diverted from your question, but I sort of don't really see it in terms like a lot of people do, I think. I don't really think consciously so much about what sounds I'm creating. I don't know what sounds I'm going to create. Sounds I could never have dreamed I would create come out, and I go "Oh, what's that?", but I never set out to do it deliberately. I've found it and then I thought, "I like that, I'll maybe work with that," but things have come from more of an intuitive place really. 
Chris Tonelli: And the meanings of the sounds that we attach to the sounds we produce as the producers of the sounds are often quite different than what different audiences are going to attach to those sounds as well, so it's a difficult question.

Phil Minton: In different cultures, of course, like in Tuvan culture [he sings briefly in the Tuvan kargyraa style ${ }^{6}$ ], [sounds carry different meanings]. I mean if you go into a post office in London [that sound would carry different meaning than in Kyzyl]. In Kyzyl, in Tuva, people are doing it—I can't say they're doing it in the street-but most people, young people, they learn to do these sounds at a very early age.

Chris Tonelli: Have you performed in Kyzyl?

Phil Minton: I have.

Chris Tonelli: Can you tell us about that?

Phil Minton: The most memorable thing was, maybe, the karaoke. Doing Tom Jones. I did, actually, jam with Tuvan musicians in a yurt together with a shaman, but I would never dare try to enter into their world. It's their world. It's their culture. I was doing what I might call open improvisations and they were cool with that. They're usually quite tonal, their music, so I just fit it in with that pentatonic tonal sound.

Maggie Nicols: I just had a memory of a story of when Phil and I were singing in Novosibirsk. Do you remember Novosibirsk?

Phil Minton: Yes, yes.

Maggie Nicols: It was quite incredible, the sort of cultural flip, in a way. Because there we were, more [she briefly speaks in her invented language] sounding almost Russian, and there were all these Russians going [she croons the following lyric, while mimicking a singer holding a microphone] "the sky was blue and high above," singing with American accents. It's really weird, this thing, how we all access each other's [sounds]: you can't help but be influenced by everything that is. I know I keep coming back to that.

Chris Tonelli: And then we walk a fine line, often, as free improvising vocalists, in terms of what we allow ourselves to be influenced by, how we bring those influences into particular performances in particular contexts as we're being influenced by the entire world of different vocal traditions that we have access to and that we've always had some level of access to since you both began in the 1950s and 1960s. How do you walk that line on stage? If you're fascinated with a particular vocal tradition that's not your own, how can you bring it in to your practice in a respectful way? Are there certain times when we prohibit ourselves from using particular techniques because of the associations they might have for the audience?

Maggie Nicols: Again, it depends. Phil and I were asked to learn overtone signing for that project with, I can't even remember his name, in Paris.

Phil Minton: Oh, yeah.

Maggie Nicols: He got all these tapes on how to do it. Neither of us did it at that point. And then, later on, I was doing another kind of practice with long notes and rhythms that I do where I can also get into a trance sometimes, and I was doing one of these notes and I thought, "well, I'll put my tongue in my mouth like you're supposed to in the roof," and all of a sudden this amazing overtone came out. But I don't use it. Very rarely.

Phil Minton: I don't either.

Maggie Nicols: If I'm absolutely deep and not thinking and it comes out, then it's meant to come out: it comes out in a context and it's right for that. But I very rarely use it. Until it's integrated. You know, once something's integrated as a vocabulary, it's like learning any language: you learn a new language, and at first it's "je pense que je suis" [she models slow construction of speech], and then, you know, when you learn to speak something fluently, then maybe [she snaps her finger]. Like, I'm learning Welsh at the moment. Again, going back to that Hawaiian thing [again referencing the talk by Dr. Kati Szego wherein Dr. Szego described Hawaiian singers and ukulele players learning 
their practice in private before performing in public]: don't come out of your bedroom until you've, you know [gained fluency in the practice you intend to perform]. It's the same with these things. Don't just use it as a gimmick just because you've learned how to do it. It comes out if it's in context and it feels authentic to you. And that's for me, rather. I can't talk for anyone else.

Phil Minton: I think the sound I use, the voice that I do use, and I feel it is part of my culture and my life, is the yodelling, jumping between the two vocal folds: the false folds and the regular folds. That I feel is part of my culture, part of my background. Although people do say, "oh, you're doing that Swiss yodelling stuff." I think "no, that's not Swiss," because my grandmother used to yodel to me when I was three years old-I was told that I was three: I wasn't quite sure, because it was somewhere far in my memory, but I was talking to my sister the other day and she said, "yeah, you were three years old." Because l'd been evacuated to this small village in Wales where my grandparents lived, and she [his grandmother] was a yodeller, but she would only yodel on Saturday mornings. And it was one of the sounds I heard when I was three, and I always wanted to yodel. I didn't know anything about Swiss yodelling, Bavarian yodelling, Pygmy yodelling, or anything. It seemed like a part of my history. The sounds that we hear, who do they belong to? Whose are they? I think there are certain stylistic things, which is something else, like the bel canto-I use that sometimes, but I'm not trying to sound like an Italian tenor or an opera singer.

Chris Tonelli: It's very complex where the lines fall, but I find that soundsingers, or free improvisers who use their voice in general, have a very heightened awareness of being respectful to those traditions in terms of what can be appropriated and how those sounds might act on particular audiences, although you never know completely the associations that audiences are going to have. Dr. Kati Szego's paper this morning quoted Dr. Beverley Diamond's work where she was saying that non-indigenous listeners often expect a heightened difference from indigenous vocalists. Do you experience particular expectations because of your bodies, because of your gender, because of your race? That's one question. I'll add another. Dr. Kara Attrep's paper today talked about how Yoko Ono and other bodies that are racialized as Asian get associated together in the press. Sainkho Namtchylak becomes "like Yoko Ono" because of her body as much as the sounds she's making. Where do the lines fall when people write about you in terms of race and gender? Do you find a kind ghettoization of race or gender? Or lines being drawn by audiences? Those are two questions. You can choose to address either.

Phil Minton: I don't think I actually sound like anything in particular as I'm improvising. I might have three seconds where, "is that a bit too. . .?" [he then gestures in a manner indicating he moves quickly to other sounds as he's improvising].

Maggie Nicols: It's shape shifting, isn't it?

Phil Minton: So, I'm not usually accused of copying any particular ethnic style. The music of my background, like I said, it was yodelling, and it was also very, very straight, basically Methodist, hymn singing. This is where I come from. [He begins to sing "All things bright and beautiful / All creatures great and small." Maggie quickly joins in]. This is where I came from.

Maggie Nicols: Gender, yeah, maybe a little bit. Critics, not audiences. I think audiences are a lot more often, sometimes, intelligent than critics, or more authentic in their responses because they're not thinking "Oh, I've got to write something." But maybe this is time to feel a bit of compassion for critics, because I'm the one that sat in front of Vincent Price's film Theatre of Blood where the guy, they think he's committed suicide, he's had a terrible review, and then he comes back to life, he's saved, and he proceeds to kill all the critics—and I've been one who's like "kill, kill, kill." But as I get older, I'm trying to be more, kind of, compassionate [laughter]. I'll try and think it must be awful to try and actually have to come up with something and actually have to find some way of expressing what you've just seen. It must be a nightmare, actually. But, yes, very often critics will sort of go on twittering.

Phil Minton: Mad and crazy. These are the sorts of thing we do get.

Maggie Nicols: Oh, we do. Yes, we do. We get incredible...

Phil Minton: "Schizophrenic voices."

Maggie Nicols: "Get these two medicated fast" is a comment l've seen on Youtube. Actually, it's very interesting, the relationships to madness, because I do think we go into altered states sometimes. Well, I certainly do go into altered states, and it is very interesting, I think, because someone very close to me was sectioned for screaming in Trafalgar Square, and I went down with my friend, and she had a camera and I screamed, and because there was a camera, it 
was suddenly all right. So I'm interested in how a lot of the things we do, if you did it in the street, you could get locked up, you could get sectioned. So how do more people come out the closet with that? Because I'm very interested in that solidarity, with these sounds being part of human expression, and some people can't stay in the closet, or won't, or can't pass. So I think we have an opportunity to spread it so that more and more people recognize, "oh, that's just. . . oh, I can. . . it's not. . ." But I'm often called weird [laughter].

Phil Minton: I was actually stopped from going on a flight in Berlin for practicing multiphonics in the Berlin airport. They had to go get the pilot. I protested. This was in the check-in. I was in the queue of the check-in talking with another musician going [he demonstrates the multiphonic he was practicing] to make some point about multiphonic singing. And then, I have an arm on my shoulder: "I'm sorry sir, we won't allow you on the flight. You're unfit to travel" [laughter]. They had to get the captain to come out. They checked to see if I had been drinking, whether I was mad.

Chris Tonelli: In my research on policing of the voice, this is the most literal example I've heard so far!

Audience Member: How long ago was that?

Phil Minton: 15 years ago, I think it was.

Maggie Nicols: Having said that, Direct Action is quite interesting because we did some solidarity actions because busking is sort of illegal, and they were clamping down and they were confiscating buskers' instruments. So it was great to go out together with the voice, because they literally couldn't confiscate our voices. There were times when, actually, you need a license to play music in the street, but they can't confiscate your voice.

Chris Tonelli: When we're talking about madness, do you feel that part of your work is to try to disassociate these rich sounds you explore with the idea that to produce them you must be in an altered state?

Maggie Nicols: Well, I'm quite happy to claim altered states, but it doesn't mean that everybody that's improvising is in an altered state. Heavens, no! For me, I like to be possessed. I remember this one woman once saying to me, this healer saying, [it's about] choosing what you're possessed by. You could be possessed by music, you could be possessed by the universe, you could be possessed by love, or you could be possessed by rage and vengefulness. I'm often possessed by those things as well, but I mean more and more I'm choosing to just be an open channel. I do feel like I'm channelling stuff, and I don't mean that in a religious sense. So I don't mind at all, but it's not a prerequisite at all to improvising.

Phil Minton: I'm in a different state than I am at the moment, where I'm trying to be sensible. This is an altered state for me [laughter].

Chris Tonelli: Okay. Two more quick questions and then I'll open the floor to questions from the audience. One quote that I find very meaningful from you, Maggie, is you've said, "liberation movements can quickly turn into their opposites. And, for me, to overcome that we need to maintain our improvisatory approach." Can you both say more about perpetual reinvention in your life, in your art, and, if you'd like, also in your politics?

Maggie Nicols: Yes, I do think things can turn into their opposites, because once things become fixed in revolutionary movements [this happens]. I think, too, it's because they are so fragile, they're so powerful, but then you've got all the reactionaries coming in. Like, say, in the Soviet Union, in the Bolshevik revolution, you had this incredible outpouring of poetry and surrealism and music, but then you've got the actual predators coming back to crush that revolution. And I'm beginning to feel that what happens in these movements is that you can't tell who are the genuine dissidents and who are the agents provocateurs, so in the end you get paranoid and when you're paranoid, of course, you become rigid, you become more fixed. Ideologies become dogmas. So I do feel to keep that openness, that flexibility, that almost anarchic quality of not actually fixing things is important. Which doesn't mean that you don't have principles-I think it's important to have principles-but if it becomes dogma, you know. So that's what I feel improvisation does. There is a skill. There's a body of knowledge. We have our own traditions, but at the same time, as I was saying before, we're constantly being aware that the universe itself is evolving and we are evolving with it. So there's a newness even in sounds that have been made a hundred times. It's happening in a new moment. I think we could be less paranoid. I think it reduces fear: improvisation. I really do. But, obviously, I don't know what I'd do if I was in a new revolutionary country and I couldn't tell a genuine dissident. Would I become just as reactionary? I don't know. But how could we create the conditions, as far as possible, to mitigate against revolution turning into reaction, as we've seen so often? 
Phil Minton: I'll talk about the voice in improvisation as opposed to instrumental improvisation, as the voice isn't actually fixed. There's no measurements of pitches or anything. I remember reading in a book about a Chinese emperor who had a musical police force. They'd go around to all the villages to check that the different pipes were of a correct length, so that they'd all be the same pitch. He would say, "if the music is different in the different villages, there's going to be anarchy." And so, what we've had in the West is this one fixed instrument, with the pitch of A440. We've had this, basically, musical oppression for the last 500 years at least. I don't know if that's any part of the question.

Maggie Nicols: I love the lateralism. Is that a word, lateralism?

Audience Member: It is now.

Chris Tonelli: All right, last question from me before I'll open up the floor. In order to do these kinds practices that are still so marginal, to use our voices in this way, we need communities and contexts that support that. We wouldn't be able to sustain it, probably, if we didn't have those. You both carry so much of free improvisation's history with you. Can you talk about the contexts and communities in your early career and the contexts and communities now that support you. How have things changed?

Phil Minton: Family? Community?

Chris Tonelli: In relationship to your artistic family. The people around you that have allowed you to do what you do, that have provided you with criticism and support and love, and that have accepted the sounds that feel true to you. Not just sounds, but your movements, your words.

Maggie Nicols: I suppose I could talk about the Little Theatre Club, that was my first support, John, Trevor, and the extended family of improvisers which I came across more in Berlin, as well when there was the first Total Music Meeting of improvisers; the Oval House — they encouraged everybody—that was a Church of England youth club and became a centre for experimentation, theatre, music, and everything; friendships, but also the people l've become close to through running workshops; and The Gathering. The Gathering, for me, is probably the deepest community; because I've learned more from The Gathering than I have from almost anything else; because I've learned about my own intolerances, my own musical preferences, my own "oh I wish they wouldn't do that," and actually learning that when I'm actually obsessed with what somebody else is doing, I'm part of the problem. If somebody isn't listening and I'm obsessed about that, I'm not listening myself. And how to then embody what it is I want. If I want more silence, to put more silence in. And feeling safe with those people outside The Gathering: so when I see them in the street, because I'm quite a self-conscious, anxious person, and so if I go somewhere and it's somebody I've known from The Gathering - I mean apart from people like Phil that I feel safe with, and there are some other musicians I feel safe with, but I haven't always felt safe with other musicians-so there's something about The Gathering. I've been crazy, I've been exposed, we've gone into really amazing territory-we've been clumsy, we've been skilled, we've been everything together-so when I see that person in a social situation, I think, "whew, I feel safe!" That to me is probably what I need. I need to feel safe in order that I can take more risks.

Phil Minton: There is an improvising community in London, and I-and Maggie does it—we travel the world. There's an improvising community in Tokyo. Last year I was in Shanghai. And we all seem to have the same basic aesthetic: in Australia, America, there's an international community of improvisers. Sadly, now, we don't have a real place in London. There are venues, but sadly the only time we all meet up is at funerals. But, I must say, there are young people coming into it. It's still an ongoing thing. How about yourself?

Chris Tonelli: Well, I've haven't been around as long as you guys.

Phil Minton: But you're a part of the community.

Chris Tonelli: Yes, but with my question I really wanted to reflect on if there have been any profound changes between your first fifteen years and the most recent fifteen years in terms of the way that improvisation communities work together, or are organized, or are funded: all of these important things.

Maggie Nicols: Well, I feel excited about what is outside the official improvising community. As much as I love the extended family members - I do, I do-I feel privileged and blessed to be part of that, but as I say, I'm convinced with 
The Gathering and I'm excited that people come who are not musicians, who are not improvisers, or not dancers, but who move, dance, play. Especially in Wales! I know it's still going in London, but I don't know what's happening because I'm not there anymore, so I don't know how it's evolving there. But, definitely, definitely, I'm excited that more and more people are enjoying improvisation. And the fact that you've got this [IICSI]! And I'm finding that everywhere more and more people are interested in improvisation as a social force. I mean, when John Stevens said "we're practising a better society," in many ways John was a voice in the wilderness in lots of ways because he sacrificed his own personal career in many ways to the point where lots of people don't even know who John Stevens is: one of the fathers of free improvisation in Europe, who influenced so many people, and not just the people he directly played with, but people who played with them and with them-the ripples are incredible. He co-founded Community Music because he wanted to share it, as community activism. So the fact that we had people like John: and there are more and more practitioners, there are so many people doing workshops, there's so much happening, and that's spreading it. So I do feel that-yes, that is very exciting, that it's becoming more and more community based.

Chris Tonelli: Kati Szego challenged us this morning to listen for the alliance in the aesthetics, and listening for that in the music of John Stevens and reflecting on those choices is, I think, an important part of improvisation studies and, of course, in both of your work. All right, now we'll open up the floor to other questions.

Audience Member: I'm wondering, when you mentioned people who have been silenced, I'm thinking about your work that you [Phil] mentioned with the housing community, and also voices where the mode of expression is not accessible: the screamer in the city square. Could you speak about that? How this fits and your personal experience of working with people whose voices are not acceptable, as well as with the people who are traditionally silenced or just ignored.

Maggie Nicols: We've both done a lot of work. I've done a lot of work as well with young offenders, with people with so-called "mental [problems]." Oh God, these labels! That's when you realize that we're all connected, we're all the same really. The fact that we're all different is what makes us the same. So I just feel that whoever I'm working with, in the probably forty-five years I've been doing community music, I realize that whatever group I'm working withwhether it's a specific group like pensioners, or kids, or a group where there's no labels and it's just people-whoever walks through the door, there are certain things that we do have in common. And it's about finding that common denominator and finding ways to make us all feel safe. It's this wounded healer thing: I think because of my own vulnerability, my own fears, I work in a way where the bottom line is that everybody feels safe first, whenever I'm working, whatever it is, whatever group. And different groups have got, obviously, very different things. But what Phil says is really interesting, because I remember doing a workshop with a load of people once, and I remember thinking, "I didn't get that, I really didn't get that," because I'm used to experiencing magic, even with excluded groups-but this particular group was so wild. But after, they were all running up and saying how much they enjoyed it; so it is that thing, not measuring it by your own thinking of "this is magic [or] that there wasn't enough magic," because it's relative to how people were feeling. And if people are feeling that they got to express themselves in a way that they hadn't, that's what's important. And we can always take it deeper, if you get a chance.

Phil Minton: I did a workshop in quite a heavy prison in America. The whole prison was divided into gangs. There was the white supremacists, the Aryan brotherhood, so I had a bunch of Aryan brotherhood; some of the quite heavy Black Panther types, the hard core black revolutionaries; and the Mexican gang-and there was a Haitian gang, and there were people from no gang at all. And so there were five groups, all in a room much smaller than this, and they had guards there too, in case there was any trouble. We started with-those who came to the workshop the other night would know_- usually start my workshops with laughter, and they were like "Who is this guy? What the fuck's going on?" It was absolutely great. And the guards were saying, "Wow, these guys are sort of slamming into each other." And then we went into lots of other areas, and afterwards, they all said that was the first time that they'd ever been all together in one room. So I thought, "this is the voice that can do this."

Maggie Nicols: It's incredible, isn't it? It's true. That's the other thing too: I remember doing some workshops, and there was one autistic boy, and they had a crash helmet on him because he was running around and screaming and screaming and screaming. And it's that thing of taking that scream and "screaming with"-and everything is music. When you have that thing that everything is music-and again, they were trying to silence him. They were saying, "he's causing us a problem." But it was like, no, no: it's all right. It's all right if he runs around screaming. It's actually okay-it's a similar sort of thing. It's just honouring: it's respect. I think the bottom line is respect. Whatever group, whoever you're working with, they know-people know if there's respect. Even if you're feeling vulnerable or anxious, for me, the bottom line is respect for who you're actually interacting with in any way-especially if you're the facilitator, because you have a power. We have a power as facilitators. Yeah, show respect!

Chris Tonelli: Other questions? 
Audience Member: When you mentioned young people coming into the improvising community, I was reminded of and wondered, is there any cross pollination between slam poetry and soundsinging or free improvising?

Maggie Nicols: Well, funny you say that, because we went to Speaker's Corner one time, and Speaker's Corner in Hyde Park is one where everybody gets up, and you get everybody from preachers, and then people heckle them. And I had done this very deep workshop: I did one of John's pieces for the whole two hours. It started with only voices, and then one extra instrument, and then another to the point where we were completely, absolutely delirious, but in a really safe way. And we called ourselves the Improvising Fundamentalists-the Ifs-and we thought we would go to Hyde Park, Speaker's Corner, and actually do something at Speaker's Corner. And who should come along but a freeform rapper, and joined in, and I had never experienced that, and it was wonderful. But apart from that, I'm sure there are connections. But that, to me, was exciting: when he saw that we were improvising, he come along and joined in, and it was incredible. We got the hecklers, of course, but it wasn't until somebody brought another instrument that we got stopped, because you don't have a license. So it's quite interesting there to do it with the voice and get away with it: just improvising in Hyde Park corner.

Phil Minton: I've worked with some slam poets. Most of them didn't know about improvising. They were mostly coming from a literary background, even if it is street. It's on one pitch [he imitates the rhythm of a rap or slam poem wordlessly on one pitch]. They were excited and interested, but I was quite surprised: voice improvising isn't really known that much on the streets. I suppose it's because people want to be taken seriously, and if you start [he briefly improvises a series of abstract staccato vocal sounds], sadly, people don't take you seriously. I did some workshops with scientists, actually. We were talking after. They weren't very responsive, actually. We went to the pub afterwards and they started to drink a bit. There was this one woman, she was a very famous biologist, and she was one of these people, she said she'd never sung. And I said, "what do you mean you've never sung? You've never gone from one note [sings a note] to [sings three more notes]." She said "no," she'd never done that, and she told a story about how at a birthday party somebody had told her, "shut up, you can't sing." And she believed it, and now she was this amazing biologist. And she said, "We wouldn't be taken seriously. It's not encouraged in the scientific community to change pitch [when speaking]." It's actually how I'm talking now, on one note: you keep your voice on one level. And I think this is a lot of rappers and slam poets [models a wordless rhythm on one pitch]. There are some I know, I think Eminem actually: he uses his voice quite a lot. But in society now it isn't encouraged to experiment too much with your voice, to change your pitch or change your voice when you're trying to make a point about something.

Audience Member: It's one thing working with prisoners or community groups, and then there's performance. There's two different worlds that encompass and challenge and bring different things to the individuals involved. Could you talk a little bit about the difference for you when you're working for a performance that would be seen by an audience?

Maggie Nicols: I think we've both done performances with the groups. I've done a hell of a lot of performances with the groups I've worked with. Not always, not every workshop leads to a performance, but a hell of a lot have, so I would do the same things. Again, I was influenced by John, because John, what he workshopped with us-he wasn't running workshops; we were his workshop, the Spontaneous Music Ensemble. It wasn't seen as a workshop at all, but he went on there later to run workshops-whatever we did, we performed. So I don't necessarily see a separation between them. Although I know there is, there doesn't have to be. If you do something really amazing with people, you can present it. I don't think we have to hide and say, "Oh, that's just for a workshop." I think it's really exciting what people do with their voices, or with their voices and other instruments as well.

Chris Tonelli: And that's a good segue, because that's the kind of blurring we're going to be experimenting with tonight at the concert at the Guelph Youth Music Centre. Since March 30th, I've been leading small vocal exploration gatherings. I've used your [to Maggie] word "gatherings," because I know it has such meaning for you, and I believe in that meaning. And tonight, Maggie, Phil, Paul Dutton, Christine Duncan, and W. Mark Sutherland are each going to bring a group that they've been working with, for a very short time really, through a different kind of structured improvisation methodology. That concert starts at 8pm tonight, and we hope you all can make it. Thank you all for coming out to the session, and thank you Maggie and Phil for your time and your knowledge.

\section{Notes}

${ }^{1}$ Nicols and Minton have each been consistently active in the U.K. and other global improvised music scenes for nearly fifty years. 
${ }^{2}$ Minton's album A Doughnut in Both Hands was one of the earliest solo vocal free jazz recording projects, and Nicols' Feminist Improvising Group was a progressive intervention into the male-privileging socio-politics of music improvisation communities in and beyond Europe in the 1970s and 1980s. Both Nicols and Minton are also important figures in the burgeoning practice of choral improvisation.

${ }^{3}$ Makhno fought for a communist political order in the Ukraine between 1906 and 1921 before going into exile in Paris. There, he produced influential anarchist criticism before his premature death in 1934.

${ }^{4}$ Joyce's experimental writing style is celebrated as "an assertion of his bodily being as a creator" (Gottfried 154). Minton's performances, similarly, lead us to celebrate and encourage participation in dynamic forms of embodiment. Vocal improvisation, en masse, can be viewed as both music and poetry composed of sounds and motions that allow us to reflect on the diverse states human embodiment entails.

${ }^{5}$ Interestingly, however, the notes to this last album reveal a serious subtext: "doughnuts in both hands" is a symbol of greed and avarice for Minton.

${ }^{6}$ Kargyraa is a form of Tuvan multiphonic "throat singing" where both the fundamental tone and a subharmonic are audible.

\section{Works Cited}

Cavarero, Adriana. For More Than One Voice. Stanford: Stanford UP, 2005. Print.

Feminist Improvising Group. Feminist Improvising Group. Feminist Improvising Group, 1979. Cassette.

The Gathering. For John Stevens. Emanem, 2003. CD.

Gottfried, Roy. The Art of Joyce's Syntax in Ulysses. London: Macmillan, 1980. Print.

Les Diaboliques. Jubilee Concert. Intakt Records, 2009. DVD.

Mike Westbrook Brass Band. Plays "For the Record." Transatlantic Records, 1976. LP.

Minton, Phil. A Doughnut in Both Hands. Rift, 1981. LP.

---. A Doughnut in One Hand. FMP, 1998. CD.

---. No Doughnuts in Hand. Emanem, 2008. CD.

---. A Doughnut's End. Fataka, 2015. LP.

Minton, Phil and Veryan Weston. Songs from a Prison Diary. Leo Records, 1993. CD.

---. Ways Out East - Ways Out West. Intakt Records, 2005. CD.

Minton, Phil, Jaap Blonk, Koichi Makigami, Paul Dutton, and David Moss. Five Men Singing. Les Disques Victo, 2004. CD.

Nicols, Maggie, Lindsay Cooper, and Joëlle Léandre. Live at the Bastille. Sync Pulse Records, 1982. LP.

Phil Minton Quartet. Mouthfull of Ecstacy. Les Disques Victo, 1996. CD.

Phil Minton Quartet with Lars Göran Ulander. Up Umeå. Blue Tower Records, 1999. CD. 
Solid Gold Cadillac. Solid Gold Cadillac. RCA Victor, 1972. LP.

The Westbrook Blake. Bright as Fire. Original Records, 1980. LP.

Westbrook, Mike. Glad Day. Enja Records, 1999. CD.

Voice. Voice. Ogun, 1977. LP. 